\title{
A FIDELIZAÇÃO DO CLIENTE COMO DIFERENCIAL COMPETITIVO NA CONQUISTA DO MERCADO
}

Edilene Mayumi Murashita Takenaka, Sérgio Luís Destro, João Vitor Minca Campioni, Dayane Magalhães Fernandes, Giovana Maria Passos Lamberti, Evandro Ricardo Justino

Curso Superior de Tecnologia em Gestão Comercial - Universidade do Oeste Paulista - UNOESTE. E-mail: edilene@unoeste.br

\section{RESUMO}

O termo "prestação de serviços" apresenta, em sua essencialidade, o ato de realizar um trabalho oferecido ou contratado por terceiros podendo ser caracterizado pela sua intangibilidade e inseparabilidade, não resultando na posse de um bem. Sendo assim, podemos entender que para as empresas que prestam serviços em caráter continuado, o relacionamento Cliente/Fornecedor torna-se visceral enquanto perdurar o compromisso, contratual ou não. O objetivo desta pesquisa foi identificar o papel dos gestores de mercado no difícil processo de retenção e conquista da tão almejada fidelização do cliente em uma empresa desenvolvedora de softwares e soluções tecnológicas. Para o desenvolvimento da presente pesquisa, fez-se necessário buscar uma compreensão particular do tema estudado fazendo uso de uma abordagem qualitativa e tendo como materiais, referencial bibliográfico, estudo documental, aplicação de questionários e entrevistas realizadas junto à empresa analisada.

Palavras-chave: Fidelização. Clientes. Gestores. Mercado. Prestação de serviços.

\section{INTRODUÇÃO E OBJETIVO}

Diante da crescente e desenfreada necessidade de consumo, oriunda de todos os segmentos da sociedade civil, setor privado e até mesmo do setor público, desencadeou-se na mesma proporção o aumento da oferta de produtos e serviços.

Porém, percebeu-se claramente que o aumento da oferta não resultou na manutenção da qualidade do que está sendo ofertado. O que percebemos muitas vezes é o contrário, ou seja, empresas que surgem preocupadas em conquistar sua fatia nesse mercado extremamente consumista, porém, desprovidas de qualquer preocupação ou foco na qualidade dos seus produtos oferecidos e serviços prestados.

O termo "prestação de serviços" apresenta, em sua essencialidade, o ato de realizar um trabalho oferecido ou contratado por terceiros - comunidade ou empresa -, incluindo assessorias, consultorias e cooperação interinstitucional e pode ser caracterizada pela intangibilidade, inseparabilidade (produzido e utilizado ao mesmo tempo), não resultando na posse de um bem.

O aumento da competitividade no setor de prestação de serviços trouxe certa homogeneidade de produtos. Dessa forma, as empresas passaram a investir na elaboração de 
estratégias que apresentem um diferencial perante seus concorrentes e assim, conquistem a fidelização de seus clientes.

De acordo com Zenone (2007, p. 25):

Um ponto fundamental na mudança estratégica das empresas é que os consumidores estão deixando os papéis tradicionais para se tornarem coparticipantes e detentores de valor. Nesse sentido, nas relações comerciais modernas, as empresas devem reconhecer que seu diálogo com os consumidores é um diálogo de iguais e tomar parte em um diálogo com consumidores que sabem o que querem requer formas de intercâmbio mais ricas e mais sutis do que aquelas com que muitas empresas estavam acostumadas.

Sendo assim, podemos entender que para as empresas que prestam serviços em caráter continuado, destacando entre outros, consultorias, assessorias e manutenções diversas, o "bom" relacionamento Cliente/Fornecedor torna-se imprescindível enquanto perdure o compromisso, contratual ou não.

Entretanto, ressaltamos que entre as várias empresas existentes no mercado, podemos encontrar aquelas que buscam produtos e serviços de qualidade, cujo foco principal não se concentra apenas na conquista de mercado e no aumento de sua lucratividade, mas sim, na retenção e fidelização do cliente conquistado.

Fidelidade é uma palavra de origem latina e pode ter diferentes significados como a lealdade, a exatidão e até mesmo a pontualidade.

Usando o termo fidelização em área mercadológica, discutimos a fidelidade do cliente em relação a determinada marca ou empresa.

Segundo Barlow (1992), a fidelização é uma estratégia que identifica, mantém e aumenta o rendimento dos melhores clientes numa relação de valor agregado, interativo e centrado no longo prazo.

O diferencial das empresas preocupadas com a fidelização do cliente está na forma de como são pensadas, em como estabelecem a sua razão de existir e, principalmente, na forma de serem geridas e mantidas ao longo de sua existência.

O objetivo desta pesquisa foi identificar o papel dos "gestores de mercado e cliente" no difícil processo de retenção e na conquista da tão almejada fidelização do cliente em uma empresa prestadora de serviços que iniciou suas atividades no ano de 1969 e que possui como atividade principal o desenvolvimento e comercialização de produtos com suporte técnico, atuando em todo o território nacional como desenvolvedora de softwares e soluções tecnológicas para 
atender o setor público na esfera Federal, Estadual e Municipal, prestando também serviços de consultorias e assessorias.

\subsection{Metodologia da Pesquisa}

O presente trabalho de pesquisa pode ser classificado como de abordagem qualitativa e teve como materiais: referencial bibliográfico, estudo documental, elaboração e aplicação do questionário e entrevista junto a funcionários pertencentes a diversos setores que compõem parte da cadeia de valor da empresa analisada e que, de alguma forma, desempenham suas funções mantendo contato direto com os clientes.

Esse tipo de estudo envolveu um número menor de entrevistados possibilitando uma maior abertura para eles se expressarem em relação ao assunto, sem preocupação com estatísticas. Utilizamos a pesquisa de campo com estudo de caso e entrevistas para coletar dados e investigar os fenômenos diretamente onde eles ocorrem. "Estudo de caso" porque restringiu o público-alvo a apenas uma unidade empresarial proporcionando assim, maior credibilidade à pesquisa, pois as abordagens foram feitas pessoalmente.

Dessa forma, num primeiro momento, desenvolvemos uma pesquisa a partir de revisão bibliográfica com levantamento de dados junto à documentação indireta em fontes primárias e secundárias.

As fundamentações teóricas proporcionadas pela leitura de obras cujos autores se destacaram em determinada área do conhecimento foram necessárias para uma melhor compreensão acerca do fenômeno em estudo.

A pesquisa bibliográfica, segundo Gil (2002) e Lakatos \& Marconi (1985), tem por finalidade posicionar o pesquisador com o que já foi anteriormente escrito sobre determinado tema, com o objetivo de permitir o esforço paralelo na análise de suas pesquisas ou manipulação de suas informações.

Em um segundo momento, foram realizadas entrevistas junto aos funcionários da empresa analisada para que pudessem expressar suas opiniões de forma clara e objetiva sobre a questão da fidelização de clientes na organização com total sigilo sobre suas identidades.

Cabe destacar que foram realizadas entrevistas e aplicação de questionários para um grupo de 6 funcionários da empresa analisada cujo procedimento foi aprovado pela Coordenadoria Central de Pesquisa (CCPq) e seus comitês de apoio ao desenvolvimento da pesquisa: CAPI 
(Comitê Assessor de Pesquisa Institucional) e CEP (Comitê de Ética em Pesquisa). (Protocolo $1393 / 2012)$

Efetuadas as etapas de pesquisa propostas, analisamos os resultados obtidos com o objetivo de definir alguns aspectos relevantes estabelecendo uma conclusão referente ao objeto de estudo.

\subsection{Resultados}

O universo da pesquisa realizada, contemplou 5 profissionais que exercem diferentes funções em diversas áreas da empresa em questão, sendo 1 representante do setor administrativo, 1 coordenador técnico, 1 agente de relacionamento (comercial), 1 gerente de clientes e 1 gerente comercial estadual.

$\mathrm{Na}$ função atual desempenhada na empresa, 2 profissionais atuam entre 1,5 anos e 02 anos e os demais, entre 10 de 15 anos. Todos trabalham na empresa a mais de 11 anos, sendo que 2 acima de 21 anos.

Em relação à escolaridade, temos apenas 1 com superior incompleto, 1 pós graduado incompleto e 3 pós graduados.

Quando questionados sobre o conhecimento das atribuições de sua atual função, todos responderam de forma positiva apontando algumas de suas atividades dentro da empresa.

Em relação ao termo "Fidelização de Cliente", todos afirmaram conhecer e acrescentaram que a mesma é apresentada como uma das principais metas para a empresa analisada.

Quando questionados sobre a existência de um programa de fidelização de cliente e de capacitação de dos colaboradores para esse fim, 3 entrevistados responderam "Sim" e 2 entrevistados respoderam "Não".

Entretanto, dos 5 entrevistados, 4 acrescentaram que a empresa disponibiliza, através da internet, vídeos que tratam sobre aprimoramento profissional nas áreas técnicas e comerciais com foco na gestão de recursos humanos e de pessoas.

Sobre a ocorrência de eventos, foi citado que a empresa organiza conferências destinadas aos Gestores e à Área Técnica para a capacitação de rotinas pertinentes a cada função.

No campo dos produtos, sistemas e serviços, todos os entrevistados afirmaram que a empresa tem investido na implantação de ferramentas para registro e acompanhamento das necessidades de melhorias dos produtos. 
Quando indagados a respeito da existência de clientes fiéis à empresa analisada, todos foram unânimes ao responder que os laços contratuais e a assistência técnica oferecida têm contribuído para a manutenção de seus clientes e a abertura de novos contratos.

\subsection{Discussão}

Ao analisarmos as informações obtidas através das entrevistas, verificamos que, apesar da ausência acerca da unanimidade sobre a existência de um programa específico de fidelização de cliente e de capacitação de dos colaboradores para esse fim, a empresa apresenta resultados positivos, com altos índices de retenção, que podem ser facilmente comprovados diante da constatação da longevidade da sua carteira de clientes (relacionamentos duradouros).

Os produtos comercializados e os serviços prestados pela empresa analisada são contratados, normalmente, por um período de 12 meses podendo ser prorrogados por mais três períodos. Tal fato pode dar a falsa impressão de fidelidade e deve ser observado pelos seus gestores.

Contudo, devemos considerar que a assistência técnica prestada pela empresa passa a ser um fator de fidelização a partir do momento em que surgem as dificuldades quer sejam de usabilidade ou de desconhecimento técnico por parte do usuário final ou mesmo de falhas reais apresentadas pelo produto (software).

Identificamos que os funcionários entrevistados desconsideram os vídeos disponibilizados na internet pela empresa analisada com foco na gestão de recursos humanos e de pessoas como uma forma de treinamento que acabam por refletir na qualidade do atendimento ao cliente.

\section{CONCLUSÃO}

A percepção dos entrevistados com relação ao tema abordado denota que cada um, ao seu modo, tem plena noção da importância da fidelização do cliente para a sobrevivência da empresa como um todo. Entretanto, não há unanimidade sobre o reconhecimento de programas ou trabalhos de treinamento e capacitação de funcionários e colaboradores para a fidelização do cliente.

Consideramos ser de extrema importância que a empresa analisada faça a exposição de forma clara a todos os colaboradores do que está sendo feito e para isso necessita ampliar, reforçar e diversificar os canais de divulgação (endomarketing), pois só através do alinhamento de 
todos cria-se a sinergia necessária que resultará na autopercepção de cada um, da importância do desempenho do seu papel dentro do processo de busca da fidelização.

Observamos que a empresa analisada possui uma carteira de clientes muito estável o que demonstra que, mesmo sem possuir um programa claramente implantado, consegue um alto índice de retenção e que, de certa forma, pode ser traduzida em fidelização.

\section{REFERÊNCIAS}

BARLOW, R. Relationship marketing: the ultimate im costumer services. Retail Control, 1992.

BERRY, L; PARASURAMAN A.; ZEITHAML, V. A. Um modelo conceitual de qualidade de serviços $e$ suas implicações para a pesquisa no futuro. Revista de Administração de Empresas. V. $46, \mathrm{n}^{\circ} 4$. pag. 96 a 107. Outubro/dezembro. 2006.

GIL. A C. Como elaborar projetos de pesquisa. São Paulo:Atlas, 2002.

KOTLER, P. \& KELLER, K. L. Administração de marketing. São Paulo: Pearson Prentice Hall, 2006.

LAKATOS, E M \& MARCONI, M A. Fundamentos de metodologia científica. São Paulo:Atlas, 1985

PEREIRA,P. F. P., BASTOS, F. C. Um estudo sobre a fidelização de clientes a partir de estratégias de marketing de relacionamento no segmento de farmácias e drogarias. SEGeT - Simpósio de Excelência em Gestão e Tecnologia. Disponível em:< http://www.aedb.br/seget/artigos09/229 Artigo Seget utima versao.pdf> Acesso em 21 ago2012.

ZENONE, L. C. CRM - Customer Relationship Management: gestão do relacionamento como cliente e a competitividade empresarial. São Paulo: Novatec, 2007. 